\title{
Gene expression profiling analysis of MENX-associated rat pituitary adenomas contributes to understand molecular mechanisms of human pituitary adenomas
}

\author{
HONGZHI ZHANG ${ }^{1}$, CHUAN XU ${ }^{2}$, NINGYANG SUN ${ }^{2}$, YINTING ZHOU ${ }^{2}$, \\ XIAOFEI YU ${ }^{1}$, XUE YAN ${ }^{2}$ and QIUJUAN ZHANG ${ }^{2}$
${ }^{1}$ Department of Neurology, Shuguang Hospital Affiliated to Shanghai University of Traditional Chinese Medicine, Shanghai 201203; ${ }^{2}$ Department of Neurology, Yueyang Hospital of Integrated Chinese and Western Medicine Affiliated to Shanghai University of Traditional Chinese Medicine, Shanghai 200437, P.R. China

Received October 17, 2014; Accepted July 10, 2015

DOI: $10.3892 / \mathrm{ol} .2015 .3904$

\begin{abstract}
The present study aimed to screen potential genes associated with pituitary adenomas to obtain further understanding with regard to the pathogenesis of pituitary adenomas. The microarray GSE23207 dataset, containing 16 pituitary adenoma samples from multiple endocrine neoplasia syndrome-associated rats and 5 normal pituitary tissue samples, was downloaded from Gene Expression Omnibus. The Linear Models for Microarray Data package was used to identify the differentially-expressed genes (DEGs) with the cut-off criteria of a $\log _{2}$ fold change (FC) $\mid>1$ and adjusted P-values of $<0.05$. The potential functions of the DEGs were predicted by functional and pathway enrichment analysis with the Database for Annotation, Visualization and Integrated Discovery. Furthermore, the interaction associations of the up- and downregulated DEGs obtained from the Search Tool for the Retrieval of Interacting Genes database were respectively revealed by the protein-protein interaction networks visualized with Cytoscape. A total of 391 upregulated and 238 downregulated DEGs in were screened in the pituitary adenoma samples. The upregulated DEGs with a higher degree in the protein-protein interaction network (e.g., $C C N A 2, C C N B 1$ and $C D C 20$ ) were significantly involved in cell cycle and cell division. Notably, PTTG1 was enriched in every functional term. These DEGs interacted with each other. The downregulated DEGs (e.g., GABRAl, GABRA4 and $G A B R B 1$ ) also interacted with each other, and were relevant to neuroactive ligand-receptor interaction; the DEG POUIF1,
\end{abstract}

Correspondence to: Dr Qiujuan Zhang, Department of Neurology, Yueyang Hospital of Integrated Chinese and Western Medicine Affiliated to Shanghai University of Traditional Chinese Medicine, 110 Ganhe Road, Shanghai 200437, P.R. China

E-mail: qiujuan_zhang@163.com

Key words: pituitary adenomas, differentially-expressed genes, pathway, protein-protein interaction interacting with $P O M C$, was correlated with the development of the pituitary gland, adenohypophysis and endocrine system. Certain DEGs, including CCNB1, CCNA2, CDC20, GABRA1, GABRA4, GABRB1, POU1F1 and POMC, and particularly $P T T G 1$, were shown to be closely involved in the pathogenesis of pituitary adenomas.

\section{Introduction}

Pituitary adenomas, accounting for $\sim 15 \%$ of all diagnosed intracranial tumors, are benign monoclonal adenomas that originate from cells of the anterior pituitary gland (1). Surgical resection, with or without adjuvant radiotherapy, is always the first line of treatment for the majority of pituitary adenomas, with the exception of prolactinomas (2). However, these treatments cannot usually control invasive pituitary adenomas due to the limited understanding of the underlying molecular mechanisms. Thereby, further research into the tumorigenesis will contribute to identifying novel therapeutic targets, which will be conductive to the development of novel therapeutic approaches for pituitary adenomas.

In past years, considerable progress has been made in identifying the key players in pituitary adenomas. A previous study has shown that the phosphoinositide 3-kinase/AKT signaling pathway is activated and enhanced in pituitary adenomas, which may be due to the mutation and amplification of an oncogene, PIK3CA (3). Mutation in another oncogene, GNAS, which encodes the guanine nucleotide-activating $\alpha$ subunit has also been suggested to be involved in pituitary hyperplasia (4). Meanwhile, a tumor suppressor aryl hydrocarbon receptor-interacting protein has been demonstrated to function in modulating cellular signaling and cAMP signaling pathways via regulation of the localization of the aryl hydrocarbon receptor (5). Also, the absence of expression of another two tumor suppressors, growth arrest and DNA-damage-inducible $\beta$ (GADD45 $\beta$ ) and $\gamma$ (GADD45 $\gamma$ ), has been observed in human pituitary adenomas $(6,7)$. Aberrant methylation of a number of genes, such as DAPK (8) and FGFR2 (9) has been confirmed to have a momentous role in pituitary tumorigenesis. Additionally, certain cell cycle regulators, such as p16, 
p21, p27, cyclin D1 and cyclin E, have also been demonstrated to function in pituitary tumorigenesis $(8,10)$. Recently, certain microRNAs (miRNA/miR) have been found to be crucial in pituitary adenomas. For instance, the expression levels of miR-431 and miR-770-5p have been found to be slightly higher in non-functioning pituitary adenomas compared to their levels in the normal pituitary gland (11). Recently, another study has shown that miRNA-dependent impairment of the HMGA/E2F1 pathway functions as pro-oncogene signaling in pituitary adenomas. Several miRNAs targeting HMGA2 (miR-326, miR-570 and miR-432) or E2F1 (miR-326 and miR-603) could inhibit the growth of pituitary cell lines (HP75 and GH3) (12).

Lee et al demonstrated that gonadotroph adenomas in MENX-affected rats closely resemble their human counterparts (13). The study further found that CYP11A1 and NUSAP1, two commonly dysregulated differentially-expressed genes (DEGs) in the gonadotroph adenomas of rats and humans, are upregulated in 77 and $95 \%$ of human gonadotroph adenomas, respectively. Using the microarray data deposited by Lee et al, the present study aimed to further identify genes that were differentially expressed between pituitary adenomas samples and normal controls. Following Gene Ontology (GO) functional and pathway enrichment analysis of the screened DEGs, Protein-Protein Interaction (PPI) networks were constructed for the up- and downregulated DEGs, respectively, in order to learn more about the interaction of proteins encoded by DEGs, which may aid in our understanding of the molecular mechanisms of pituitary adenomas. The results are expected to assist in elucidating the etiology of pituitary adenomas, and provide novel insights for the clinical diagnosis of this disease.

\section{Materials and methods}

Affymetrixmicroarray data. The gene expression profile data of GSE23207 (13) were acquired from Gene Expression Omnibus (GEO; http://www.ncbi.nlm.nih.gov/geo/), which was based on the platform of the GPL6247 [RaGene-1_0-st] Affymetrix Rat Gene 1.0 ST Array. This dataset contains 16 samples of pituitary homozygous mutants (p27Kip1/Cdknb1) from MENX-associated rats, aged 7-8 months, with large tumors 1-2 $\mathrm{mm}$ in size, and 5 samples of normal pituitary tissues purchased from BioChain Inc. (Hayward, CA, USA).

Data preprocessing and screening of DEGs. CEL files and probe annotation files were downloaded, and the gene expression data of all the samples were preprocessed via the Robust Multichip Averaging background correction (14), quantile normalization and probe summarization methods using the Oligo package (15). The Linear Models for Microarray Data package (16) of $\mathrm{R}$ was used for the identification of genes that were significantly differentially expressed in pituitary adenomas samples. The raw P-value was adjusted by the Benjamin and Hochberg method (17), and only the genes meeting the cut-off criteria of a $\mid \log _{2}$ fold change (FC) $\mid$ of $>1$ and an adjusted P-value of $<0.05$ were selected as DEGs.

GO and pathway enrichment analysis. The Database for Annotation, Visualization and Integrated Discovery (DAVID) gene functional classification tool now provides a comprehensive set of novel and powerful tools for researchers to understand the biological meaning behind abundant genes (18). Pathway enrichment analysis was conducted to identify the significant metabolic pathways for the DEGs (19). $\mathrm{P}<0.05$ and a count number of $>2$ were used as the cut-off criteria for GO and Kyoto Encyclopedia of Genes and Genomes (KEGG) pathway enrichment analyses by DAVID.

PPI network construction. The Search Tool for the Retrieval of Interacting Genes database was used to analyze the PPIs for DEGs by calculating the combined scores (20), and a score $>0.4$ was chosen as the cut-off. Next, PPI networks for upand downregulated DEGs were visualized using Cytoscape (http://cytoscape.org/) (21). The highly connected nodes (hub proteins) were detected by calculating the degree of each node protein based on the scale-free property of interaction networks (22).

\section{Results}

Identification of DEGs. Based on the cut-off criteria, a total of 629 DEGs were screened from the pituitary adenomas samples, including 391 upregulated and 238 downregulated DEGs.

Enrichment analysis of up- and downregulated DEGs. According to GO functional annotation, the upregulated DEGs were mainly enriched in GO terms associated with the cell cycle and cell division. For example, DEGs such as CCNA2, NUSAP1, CCNB1, CENPF, CDC20 and SPC25 were significantly involved in the cell cycle $\left(\mathrm{P}=1.08 \times 10^{-12}\right)$; NUSAP1, $C E N P F, S P C 25, C D C 20$ and $C C N B 1$ were involved in the $\mathrm{M}$ phase $\left(\mathrm{P}=3.09 \times 10^{-11}\right)$; and DEGs such as $C C N B 1, S P C 25$, TOP2A, CDC20 and CCNA2 were correlated with cell division $\left(\mathrm{P}=1.25 \times 10^{-7}\right)$. Notably, PTTG1 was found to be enriched in every GO term (Table I). The downregulated DEGs, such as KCND3, GABRA1, GABRA4 and GABRB1, were markedly associated with ion transport $\left(\mathrm{P}=6.05 \times 10^{-7}\right)$; DEGs such as $K C N J 5, K C N D 3, K C N J 6$ and $K C N T 2$ were relevant to metal ion transport $\left(\mathrm{P}=3.87 \times 10^{-6}\right)$ and potassium ion transport $\left(\mathrm{P}=7.01 \times 10^{-5}\right)$; DEGs such as DRD2, POU1F1 and GHRHR were distinctly associated with the positive regulation of multicellular organism growth $\left(\mathrm{P}=2.47 \times 10^{-4}\right)$, pituitary gland development $\left(\mathrm{P}=5.70 \times 10^{-4}\right)$, adenohypophysis development $\left(\mathrm{P}=8.52 \times 10^{-4}\right)$, diencephalon development $\left(\mathrm{P}=1.24 \times 10^{-3}\right)$ and endocrine system development $\left(\mathrm{P}=6.09 \times 10^{-3}\right)$; and $\mathrm{DEG}$ such as NOTCH2, ERBB4 and POU1F1 were involved in cell fate commitment $\left(\mathrm{P}=3.22 \times 10^{-2}\right)$ and the regulation of cell proliferation $\left(\mathrm{P}=4.55 \times 10^{-2}\right)($ Table II).

According to the KEGG pathway enrichment analysis, the upregulated DEGs were mainly enriched in 10 pathways. For example, $C D C 20, C C N B 1, C C N B 2, B U B 1, C D K N 1 A$ and $M C M 3$ were enriched in the pathway of the cell cycle $\left(\mathrm{P}=5.01 \times 10^{-7}\right)$; $C D C 20, C C N B 1, C C N B 2, B U B 1$ and $P L K 1$ were distinctly enriched in the pathway of oocyte meiosis $\left(\mathrm{P}=1.058 \times 10^{-3}\right)$; $C C N B 1, C C N B 2, C C N A 2, B U B 1$ and $P L K 1$ were significantly enriched in the pathway of progesterone-mediated oocyte maturation $\left(\mathrm{P}=1.150 \times 10^{-3}\right)$; and $C D K N 1 A, C C N B 1, C C N B 2$ and $C A S P 8$ were markedly enriched in the $\mathrm{p} 53$ signaling pathway $\left(\mathrm{P}=3.4841 \times 10^{-2}\right)$ (Table III). Meanwhile, the downregulated 


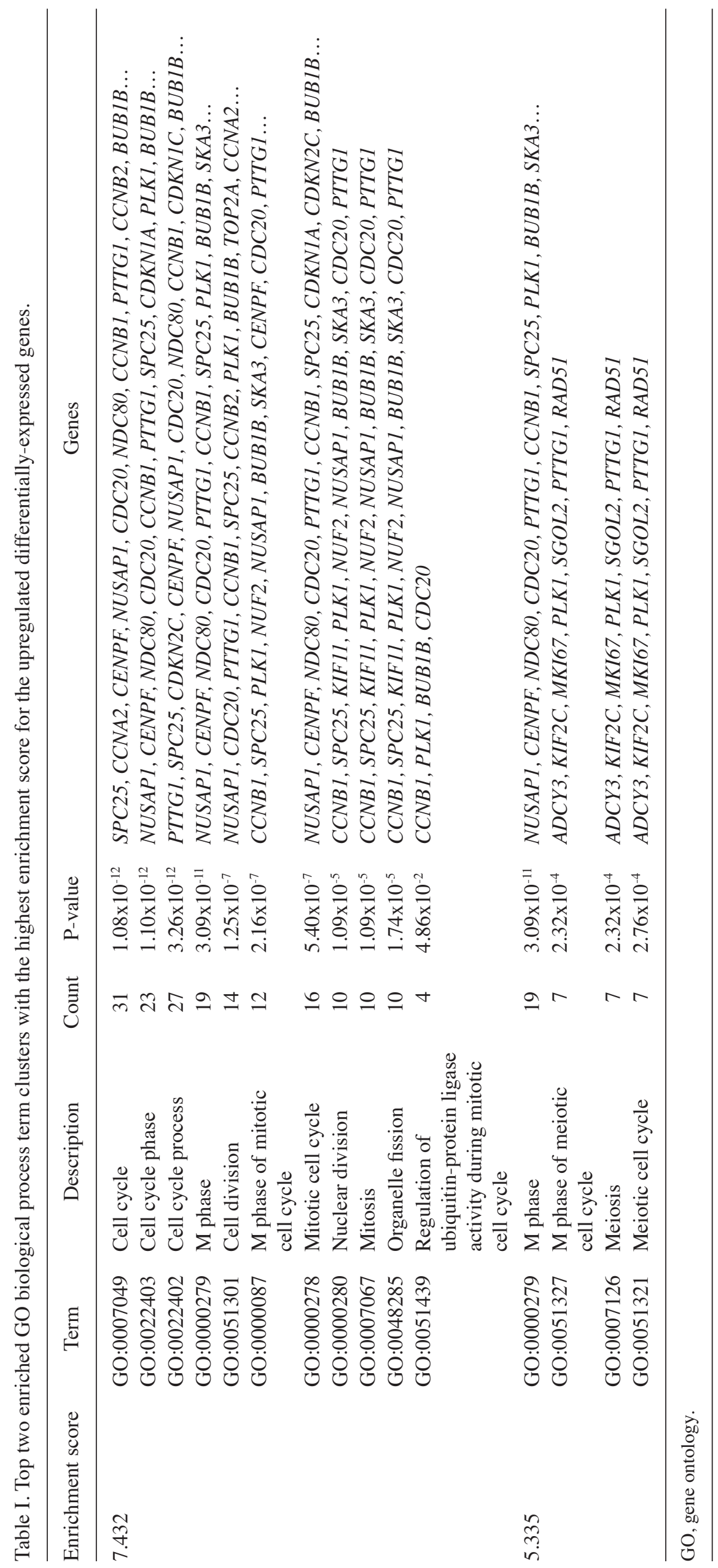




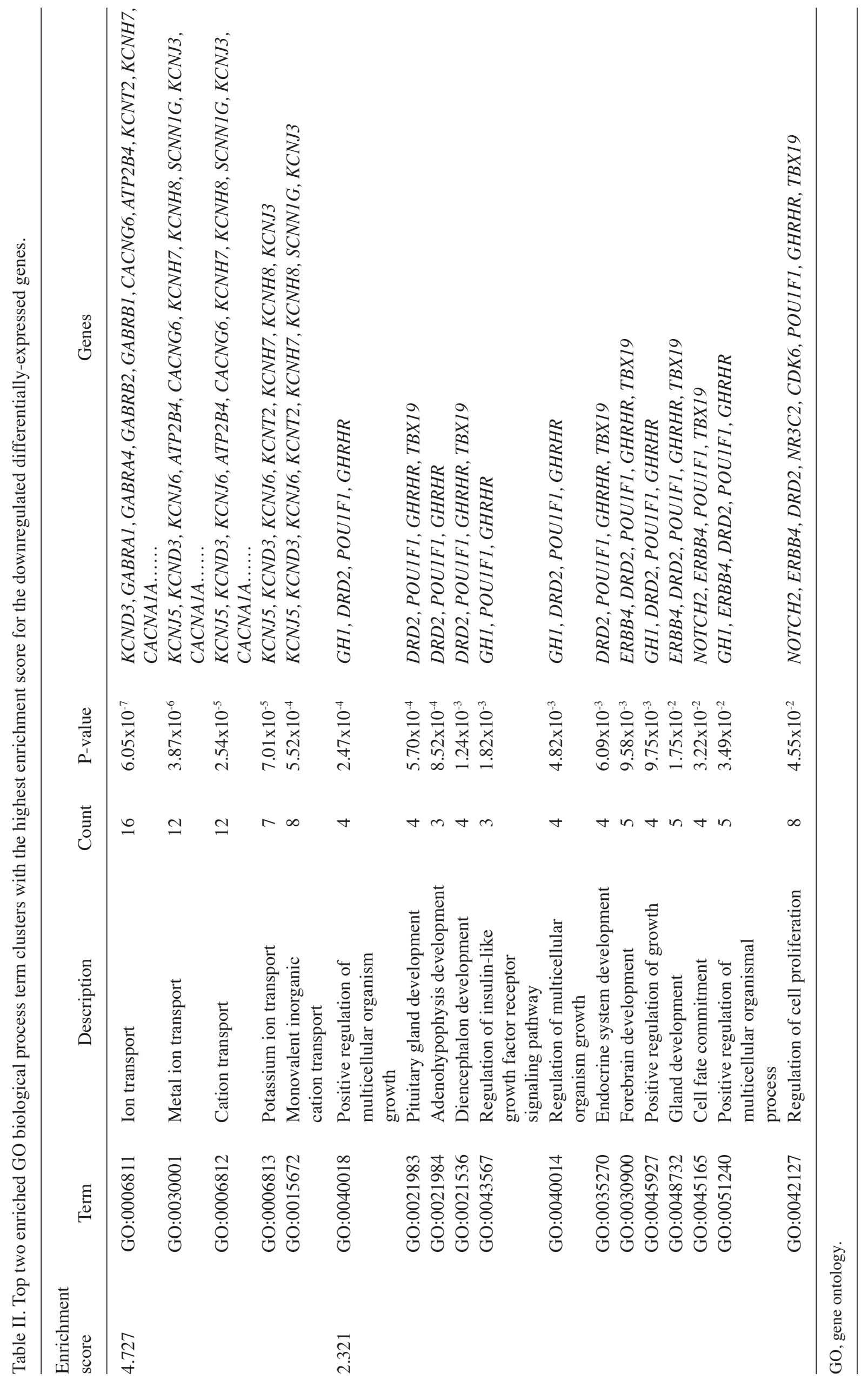







Table IV. Upregulated DEGs with connection degrees of $>30$ and the downregulated DEGs with connection degrees of at least 3 in the protein-protein interaction networks.

\begin{tabular}{|c|c|}
\hline Category & Degree \\
\hline \multicolumn{2}{|c|}{ Upregulated DEGs } \\
\hline$C D K 1$ & 51 \\
\hline$C C N B 1$ & 47 \\
\hline CCNA2 & 46 \\
\hline$B U B 1$ & 44 \\
\hline ECT2 & 43 \\
\hline$T P X 2$ & 42 \\
\hline NDC80 & 42 \\
\hline PRCl & 42 \\
\hline NUSAP1 & 41 \\
\hline TOP2A & 41 \\
\hline$C C N B 2$ & 41 \\
\hline$P B K$ & 41 \\
\hline$R A C G A P 1$ & 41 \\
\hline$T T K$ & 41 \\
\hline$P I K 1$ & 40 \\
\hline$S P C 25$ & 40 \\
\hline$B U B 1 B$ & 40 \\
\hline CENPF & 40 \\
\hline$C D K N 3$ & 39 \\
\hline$N U F 2$ & 38 \\
\hline$C D C 20$ & 38 \\
\hline KIF 11 & 38 \\
\hline$D L G A P 5$ & 38 \\
\hline SGOL2 & 37 \\
\hline$D T L$ & 36 \\
\hline$K I F 20 A$ & 36 \\
\hline$C D C A 2$ & 36 \\
\hline$K I F 20 B$ & 35 \\
\hline ESCO2 & 35 \\
\hline RAD51 & 34 \\
\hline$A R H G A P 11 A$ & 34 \\
\hline$C K A P 2$ & 33 \\
\hline$H M M R$ & 33 \\
\hline$K I F 2 C$ & 32 \\
\hline$D E P D C 1$ & 32 \\
\hline
\end{tabular}

Downregulated DEGs

$P O M C$

GSTA4

GSTA1

POU1F1

ERBB4

GABRAl

MGST1

GABRA4

GSTM7

ALDH2

GH1

$N R 4 A 2$

$M A O B$
Table IV. Continued.

\begin{tabular}{lr}
\hline Category & Degree \\
\hline$K C N D 3$ & 3 \\
$N O T C H 2$ & 3 \\
$G A B R B 1$ & 3
\end{tabular}

DEGs, differentially-expressed genes.

DEGs were mainly enriched in 7 pathways. GH1, GABRA1, $G A B R A 4$ and $G A B R B 1$ were enriched in the pathway of neuroactive ligand-receptor interaction $\left(\mathrm{P}=4.35 \times 10^{-4}\right) ; M A O B$, $A L D H 2$ and $A L D H 1 A 7$ were mainly enriched in the pathways of histidine metabolism $\left(\mathrm{P}=1.2476 \times 10^{-2}\right)$ and tryptophan metabolism $\left(\mathrm{P}=3.7487 \times 10^{-2}\right)$; ATP2B4, ERBB4 and PLCG2 were enriched in the calcium signaling pathway $\left(\mathrm{P}=3.9919 \times 10^{-2}\right)$; and GSTA4, MGST1, GSTM7 were significantly enriched in the pathways of drug metabolism $\left(\mathrm{P}=1.4397 \times 10^{-2}\right)$ and glutathione metabolism $\left(\mathrm{P}=4.9294 \times 10^{-2}\right)$ (Table III).

Analysis of PPI network. The PPI networks constructed with the up- and downregulated DEGs consisted of 1,044 and 69 PPI pairs, respectively. In the former, PTTG1, along with CCNB1, CCNA2, SPC25, CENPF, NUSAP1, CDC20, TOP2A and $B U B 1$, were observed to interact with each other (Fig. 1). Within the PPI network built with downregulated DEGs, GABRA1, GABRA4, GABRB1 and GABRB1 were observed to interact with each other; GSTA3, GSTA4, GSTM7 and MGST1 were also found to interact with each other, and $P O U 1 F 1$ was observed to interact with POMC (Fig. 2). The connection degrees of the top $15 \%$ highly-connected upregulated DEGs were each $>30$, and those of $C D K 1, C C N B 1, C C N A 2$ and $B U B 1$ were 51, 47, 46 and 44, respectively (Table IV). The top $20 \%$ highly-connected downregulated DEGs all had connection degrees of at least 3, and the degrees of POMC, GSTA4, POU1F1, ERBB4, KCND3 and NOTCH2 were 6, 5, 4, 4, 3 and 3 , respectively (Table IV).

\section{Discussion}

In the present study, 391 DEGs were identified to be significantly upregulated and 238 were significantly downregulated in the pituitary adenomas samples. According to the constructed PPI network with the upregulated DEGs, PTTG1 interacted with other DEGs with higher connection degrees, such as CCNB1, CCNA2, SPC25, CENPF, NUSAP1, CDC20, $T O P 2 A$ and $B U B 1$.

$P T T G 1$, a tumorigenic gene in vivo (23), is abundantly expressed in pituitary tumors (24). As a securin protein, PTTG1 is correlated with the mitotic checkpoint that prevents abnormal chromosome segregation (25), and peaks at the $\mathrm{G}_{2} / \mathrm{M}$ phase (26). The overexpression of PTTG1 results in cell transformation and induces aneuploidy (27), and this exists in $>90 \%$ of pituitary tumors (28). PTTG1, together with CCNB1, CCNA2, $B U B 1, S P C 25, C E N P F, N U S A P 1, T O P 2 A$ and $C D C 20$, were all found to be enriched in GO terms associated with the cell cycle or cell division, which are indispensable for tumor growth. It 


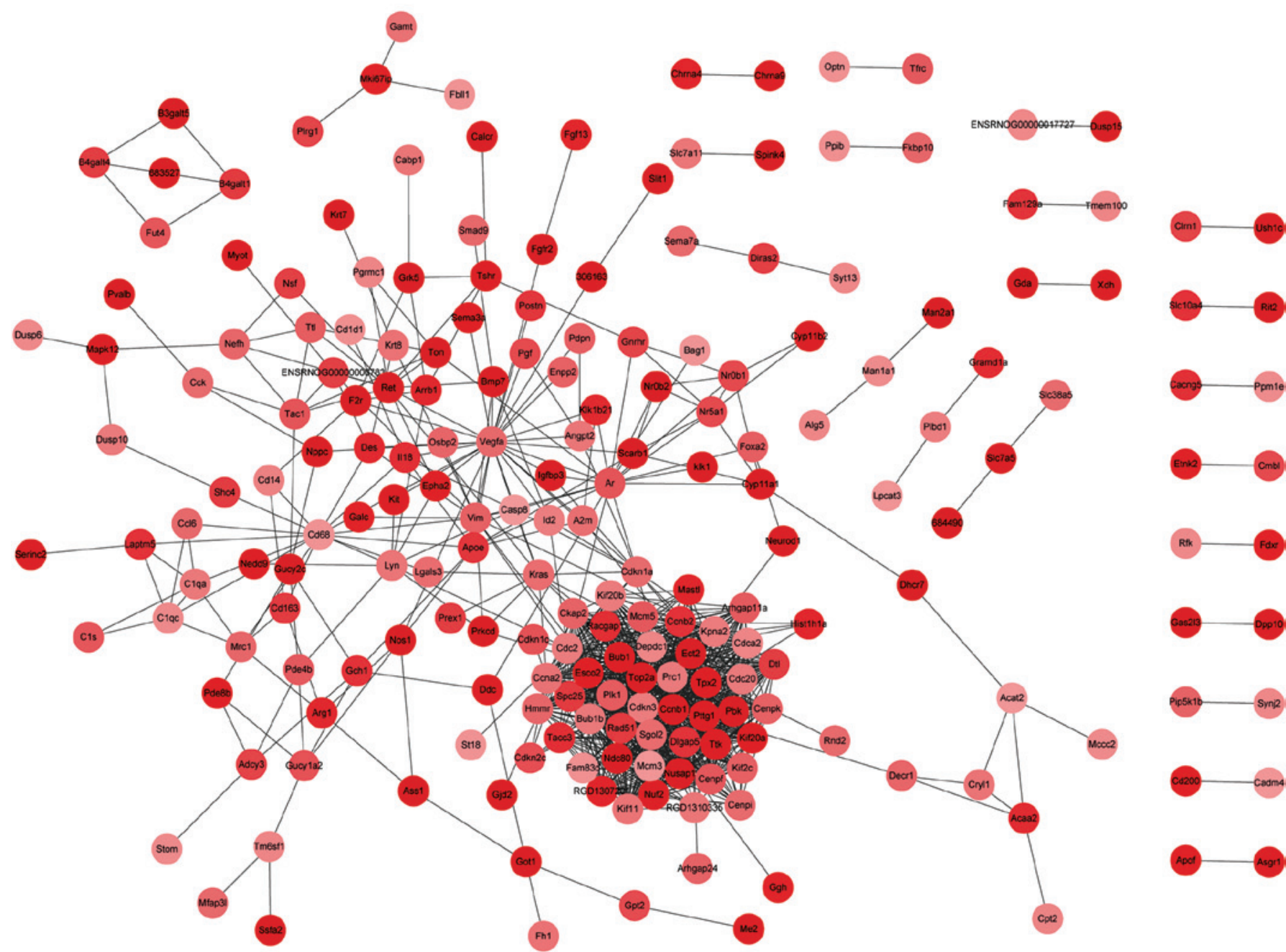

Figure 1. Protein-protein interaction network constructed with the upregulated differentially-expressed genes. Different shades of nodes colors represent the degree of up- or downregulation.

has been reported that $C D C 20$ is involved in the degradation of PTTG1-encoding products (29). Meanwhile, previous studies have also reported the abnormal expression of CCNBI (30), $C C N A 2$ (31), and $B U B 1$ (32) in pituitary adenomas. Furthermore, $C C N B 1$ was enriched in the p53 signaling pathway. PTTG1-encoding protein can cooperate with 553 to take part in cell apoptosis and DNA damage/repair $(33,34)$. Altered p53 expression has been reported in pituitary carcinomas (35). Also, PTTG1 can activate $\beta$-fibroblast growth factor, cyclin D3 and c-myc to promote cell proliferation $(36,37)$. Therefore, PTTG1 may play a crucial role in the occurrence of pituitary adenomas via interaction with $C C N B 1, C C N A 2, C E N P F, N U S A P 1$, $C D C 20, T O P 2 A, B U B 1$ and 553 .

Within the PPI network constructed with downregulated DEGs, GABRAl, GABRA4 and GABRB1 had higher degrees of connection to other genes. These genes were enriched in the pathway of neuroactive ligand-receptor interaction. GABRAl, GABRA4 and GABRB1 encode $\gamma$-aminobutyric acid (GABA) receptors. GABA is the major inhibitory neurotransmitter in the mammalian brain and may act as a paracrine or autocrine regulating factor in the human pituitary gland and human pituitary growth hormone adenomas (38). It has been reported that GABA has a specific effect on the electrical activity of a tumoral line of rat pituitary cells, and that it inhibits prolactin secretion directly at the pituitary level (39). Additionally, POU1F1 was also observed to have a higher connection degree in the PPI network. This gene encoding a member of the POU family of transcription factors (40), was correlated with the development of the pituitary gland, adenohypophysis and endocrine system. In humans, POU1FI mutation has been shown to be associated with combined pituitary hormone deficiency (41). POUIF1 is also implicated in cell growth and prevents cell apoptosis (42). In the present study, it was observed to interact with $P O M C$, which encodes a polypeptide hormone precursor. The encoded polypeptide hormone precursor is synthesized mainly in corticotrophin cells of the anterior pituitary (43). A previous study has shown that in silent pituitary adenomas, POMC mRNA has a diffuse low level or is absent (44). Thus, GABRA1, GABRA4, GABRB1, POU1F1 and POMC may also have critical roles in pituitary adenoma occurrence via close interaction.

In conclusion, upregulated DEGs, such as those associated with the cell cycle or cell division (e.g., CCNB1, CCNA2, BUB1, CENPF, NUSAP1, CDC20, TOP2A and particularly PTTG1) and downregulated DEGs, such as those relevant to neuroactive ligand-receptor interaction (e.g., GABRAl, GABRA4 and 


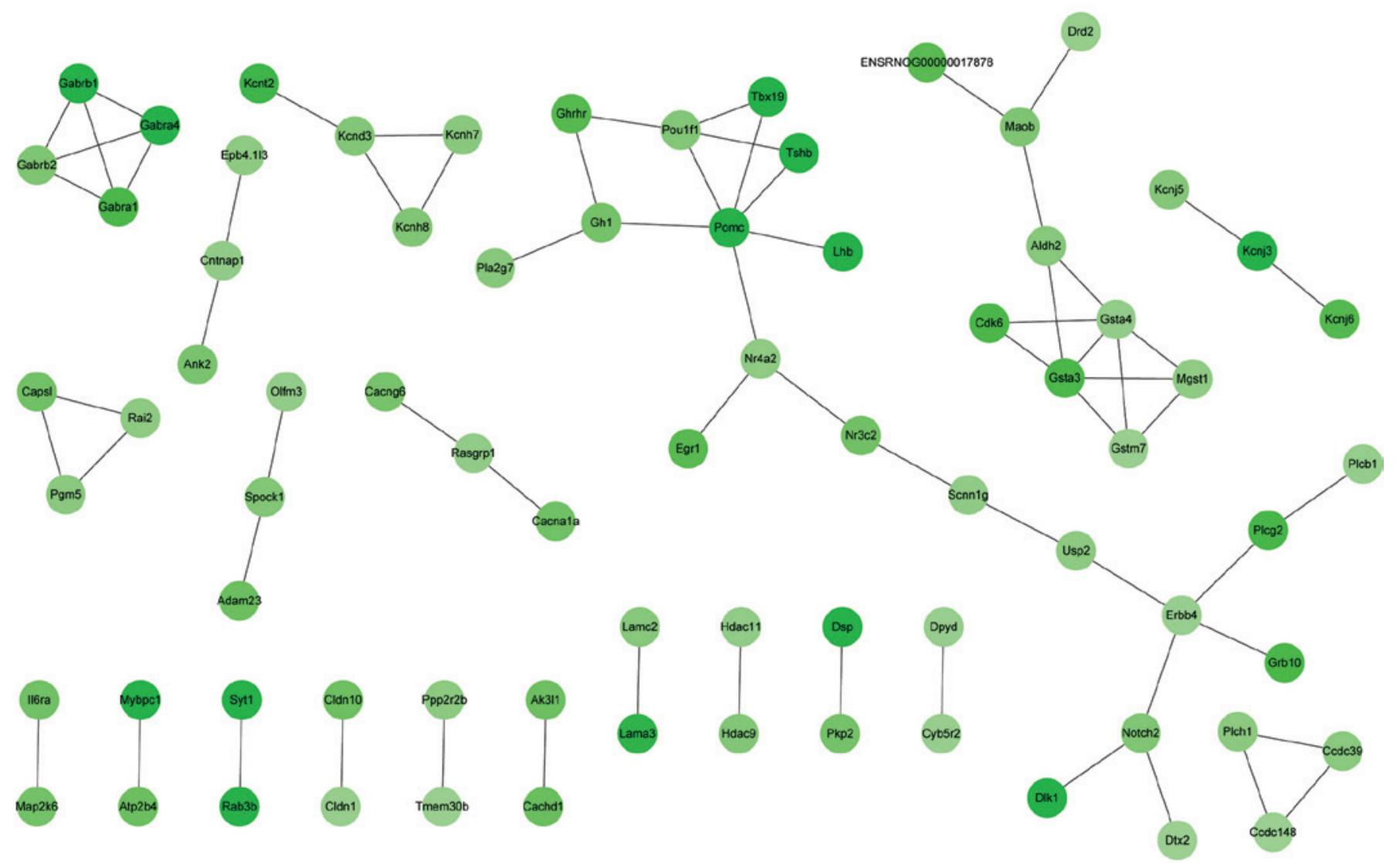

Figure 2. Protein-protein interaction network constructed with the downregulated differentially-expressed genes. Different shades of nodes colors represent the degree of up- or downregulation.

GABRB1), as well as those correlated with the development of the pituitary gland, adenohypophysis and endocrine system (e.g., POU1F1) may have essential roles in the pathogenesis of pituitary adenomas. The present study provides novel information for the clinical diagnosis of this disease.

\section{Acknowledgements}

This study was supported by grants from the National Natural Science Foundation of China (no. 81273732/H2708) and the Shanghai Educational Commission Funding Project (no. 2012JW68).

\section{References}

1. Chesnokova V and Melmed S: Pituitary tumour-transforming gene (PTTG) and pituitary senescence. Horm Res 71 (Suppl 2): 82-87, 2009.

2. Pereira AM and Biermasz NR: Treatment of nonfunctioning pituitary adenomas: What were the contributions of the last 10 years? A critical view. Ann Endocrinol (Paris) 73: 111-116, 2012.

3. Lin Y, Jiang X, Shen Y, Li M, Ma H, Xing M and Lu Y: Frequent mutations and amplifications of the PIK3CA gene in pituitary tumors. Endocr Relat Cancer 16: 301-310, 2009.

4. Vortmeyer AO, Glasker S, Mehta GU, Abu-Asab MS, Smith JH, Zhuang Z, Collins MT and Oldfield EH: Somatic GNAS mutation causes widespread and diffuse pituitary disease in acromegalic patients with McCune-Albright syndrome. J Clin Endocrinol Metab 97: 2404-2413, 2012.

5. Vandeva S, Tichomirowa MA, Zacharieva S, Daly AF and Beckers A: Genetic factors in the development of pituitary adenomas. Endocr Dev 17: 121-133, 2010.
6. Mezzomo LC, Gonzales PH, Pesce FG, Kretzmann Filho N, Ferreira NP, Oliveira MC and Kohek MB: Expression of cell grow th negative regulators MEG3 and GADD45 $\gamma$ is lost in most sporadic human pituitary adenomas. Pituitary 15: 420-427, 2012.

7. Michaelis KA, Knox AJ, Xu M, Kiseljak-Vassiliades K, Edwards MG, Geraci M, Kleinschmidt-DeMasters BK, Lillehei KO and Wierman ME: Identification of growth arrest and DNA-damage-inducible gene beta (GADD45beta) as a novel tumor suppressor in pituitary gonadotrope tumors. Endocrinology 152: 3603-3613, 2011.

8. Farrell WE: Epigenetic mechanisms of tumorigenesis. Horm Metab Res 37: 361-368, 2005.

9. Ezzat S: Epigenetic control in pituitary tumors. Endocr J 55: 951-957, 2008

10. Melmed S: Pathogenesis of pituitary tumors. Nat Rev Endocrinol 7: 257-266, 2011.

11. Cheunsuchon P, Zhou Y, Zhang X, Lee H, Chen W, Nakayama Y, Rice KA, Tessa Hedley-Whyte E, Swearingen B and Klibanski A: Silencing of the imprinted DLK1-MEG3 locus in human clinically nonfunctioning pituitary adenomas. Am J Pathol 179: 2120-2130, 2011

12. D'angelo D, Palmieri D, Mussnich P, Roche M, Wierinckx A, Raverot G, Fedele M, Croce CM, Trouillas J, Fusco A, et al: Altered microRNA expression profile in human pituitary GH adenomas: Down-regulation of miRNA targeting HMGA1, HMGA2 and E2F1. J Clin Endocrinol Metab 97: 2011-3482, 2012

13. Lee M, Marinoni I, Irmler M, Psaras T, Honegger JB Beschorner R, Anastasov N, Beckers J, Theodoropoulou M, Roncaroli F, et al: Transcriptome analysis of MENX-associated rat pituitary adenomas identifies novel molecular mechanisms involved in the pathogenesis of human pituitary gonadotroph adenomas. Acta Neuropathol 126: 137-150, 2013.

14. Irizarry RA, Hobbs B, Collin F, Beazer-Barclay YD, Antonellis KJ, Scherf U and Speed TP: Exploration, normalization and summaries of high density oligonucleotide array probe level data. Biostatistics 4: 249-264, 2003. 
15. Carvalho BS and Irizarry RA: A framework for oligonucleotide microarray preprocessing. Bioinformatics 26: 2363-2367, 2010.

16. Smyth GK: Linear models and empirical bayes methods for assessing differential expression in microarray experiments. Stat Appl Genet Mol Biol 3, 2004.

17. Benjamini Y and Hochberg Y: Controlling the false discovery rate: A practical and powerful approach to multiple testing. J R Stat Soc Ser B 57: 289-300, 1995.

18. Huang da W, Sherman BT and Lempicki RA: Systematic and integrative analysis of large gene lists using DAVID bioinformatics resources. Nat Protoc 4: 44-57, 2008

19. Huang DW, Sherman BT and Lempicki RA: Bioinformatics enrichment tools: Paths toward the comprehensive functional analysis of large gene lists. Nucleic Acids Res 37: 1-13, 2009.

20. Von Mering C, Huynen M, Jaeggi D, Schmidt S, Bork P and Snel B: STRING: A database of predicted functional associations between proteins. Nucleic Acids Res 31: 258-261, 2003

21. Kohl M, Wiese S and Warscheid B: Cytoscape: Software for visualization and analysis of biological networks. Methods Mol Biol 696: 291-303, 2013

22. He $X$ and Zhang J: Why do hubs tend to be essential in protein networks? PLoS genetics 2: e88, 2006.

23. Zhang X, Horwitz GA, Prezant TR, Valentini A, Nakashima M, Bronstein MD and Melmed S: Structure, expression and function of human pituitary tumor-transforming gene (PTTG). Mo Endocrinol 13: 156-166, 1999.

24. Chen L, Puri R, Lefkowitz EJ and Kakar SS: Identification of the human pituitary tumor transforming gene (hPTTG) family: Molecular structure, expression and chromosomal localization Gene 248: 41-50, 2000.

25. Quereda V and Malumbres M: Cell cycle control of pituitary development and disease. J Mol Endocrinol 42: 75-86, 2009.

26. Yu R, Ren SG, Horwitz GA, Wang Z and Melmed S: Pituitary tumor transforming gene (PTTG) regulates placental JEG-3 cell division and survival: Evidence from live cell imaging. Mol Endocrinol 14: 1137-1146, 2000

27. Yu R, Lu W, Chen J, Mccabe CJ and Melmed S: Overexpressed pituitary tumor-transforming gene causes aneuploidy in live human cells. Endocrinology 144: 4991-4998, 2003.

28. Zhang X, Horwitz GA, Heaney AP, Nakashima M, Prezant TR, Bronstein MD and Melmed S: Pituitary tumor transforming gene (PTTG) expression in pituitary adenomas. J Clin Endocr Metab 84: 761-767, 1999.

29. Zur A and Brandeis M: Securin degradation is mediated by fzy and fzr and is required for complete chromatid separation but not for cytokinesis. EMBO J 20: 792-801, 2001.

30. Raverot G, Wierinckx A, Dantony E, Auger C, Chapas G, Villeneuve L, Brue T, Figarella-Branger D, Roy P, Jouanneau E, et al: Prognostic factors in prolactin pituitary tumors: Clinical, histological and molecular data from a series of 94 patients with a long postoperative follow-up. J Clin Endocr Metab 95: 1708-1716, 2010.
31. Leone V, Langella C, D'Angelo D, Mussnich P, Wierinckx A, Terracciano L, Raverot G, Lachuer J, Rotondi S, Jaffrain-Rea ML, et al: Mir-23b and miR-130b expression is downregulated in pituitary adenomas. Mol Cell Endocrinol 390: 1-7, 2014.

32. Yoshida D, Nomura R and Teramoto A: Signalling pathway mediated by CXCR7, an alternative chemokine receptor for stromal-cell derived factor- $1 \alpha$, in AtT20 mouse adrenocorticotrophic hormone-secreting pituitary adenoma cells. J Neuroendocrinol 21: 481-488, 2009.

33. Yu R, Heaney AP, Lu W, Chen J and Melmed S: Pituitary tumor transforming gene causes aneuploidy and p53-dependent and p53-independent apoptosis. J Biol Chem 275: 36502-36505, 2000.

34. Hamid T and Kakar SS: PTTG/securin activates expression of p53 and modulates its function. Mol Cancer 3: 18, 2004.

35. Thapar K, Scheithauer BW, Kovacs K, Pernicone PJ, Laws ER Jr: p53 expression in pituitary adenomas and carcinomas: Correlation with invasiveness and tumor growth fractions. Neurosurgery 38: 765-770, 1996

36. Mccabe C, Khaira J, Boelaert K, Heaney AP, Tannahill LA, Hussain S, Mitchell R, Olliff J, Sheppard MC, Franklyn JA and Gittoes NJ: Expression of pituitary tumour transforming gene (PTTG) and fibroblast growth factor-2 (FGF-2) in human pituitary adenomas: Relationships to clinical tumour behaviour. Clin Endocrinol (Oxf) 58: 141-150, 2003.

37. Pei L: Identification of c-myc as a down-stream target for pituitary tumor-transforming gene. J Biol Chem 276: 8484-8491, 2001.

38. End K, Gamel-Didelon K, Jung H, Tolnay M, Lüdecke D, Gratzl M and Mayerhofer A: Receptors and sites of synthesis and storage of gamma-aminobutyric acid in human pituitary glands and in growth hormone adenomas. Am J Clin Pathol 124: 550-558, 2005.

39. Israel J, Dufy B, Gourdji D and Vincent J: Effects of GABA on electrical properties of cultured rat pituitary tumor cells: An intracellular recording study. Life Sci 29: 351-359, 1981.

40. Cohen LE, Wondisford FE and Radovick S: Role of Pit-1 in the gene expression of growth hormone, prolactin and thyrotropin. Endocrinol Metab Clin North Am 25: 523-540, 1996.

41. Quentien MH, Barlier A, Franc JL, Pellegrini I, Brue T and Enjalbert A: Pituitary transcription factors: From congenital deficiencies to gene therapy. J Neuroendocrinol 18: 633-642, 2006.

42. Pellegrini I, Roche C, Quentien MH, Ferrand M, Gunz G, Thirion S, Bagnis C, Enjalbert A and Franc JL: Involvement of the pituitary-specific transcription factor pit-1 in somatolactotrope cell growth and death: An approach using dominant-negative pit-1 mutants. Mol Endocrinol 20: 3212-3227, 2006.

43. Millington GW: Proopiomelanocortin (POMC): The cutaneous roles of its melanocortin products and receptors. Clin Exp Dermatol 31: 407-412, 2006.

44. Stefaneanu L, Kovacs K, Horvath E and Lloyd RV: In situ hybridization study of pro-opiomelanocortin (POMC) gene expression in human pituitary corticotrophs and their adenomas. Virchows Arch A Pathol Anat Histopathol 419: 107-113, 1991. 